\title{
Study on the Development Path of Homestay Industry in Ancient Town Under the Background of Integration of Culture and Tourism — Take Dujiangyan as an Example
}

\author{
Geng Baojiang, Guo Dandan* \\ Tourism College, Sichuan Agricultural University, Dujiangyan, China \\ Email address: \\ 429809942@qq.com (Geng Baojiang), Ddan1102@126.com (Guo Dandan) \\ ${ }^{*}$ Corresponding author
}

To cite this article:

Geng Baojiang, Guo Dandan. Study on the Development Path of Homestay Industry in Ancient Town Under the Background of Integration of Culture and Tourism — Take Dujiangyan as an Example. Science Journal of Business and Management. Vol. 8, No. 4, 2020, pp. 161-166. doi: $10.11648 /$ j.sjbm.20200804.12

Received: December 8, 2020; Accepted: January 9, 2021; Published: January 15, 2021

\begin{abstract}
In recent years, Sichuan Province has vigorously promoted the integration of cultural and tourism development and actively guided the transformation and development of the tourism industry in various regions. The development of the homestay industry has ushered in new development opportunities. Based on the research and analysis of the development status of the homestay industry in the ancient town of Dujiangyan, this study puts forward the path exploration of the integrated development of the homestay industry and the cultural tourism industry based on the background of the integration of cultural and tourism development, it is expected to serve as a reference for the development of the local homestay industry. Through literature research, field research and in-depth interviews and other research methods, it is found that Dujiangyan ancient town homestay exists in the development:(1) Single homestays are in their own ranks, and brand awareness is weak; (2) The market access threshold is low and lack of professional talents; (3) The regional cultural characteristics are not obvious, and the convergence of products and services is gradually revealed; (4) The uneven operation level of shared homestay network. In order to promote the development of the local homestay industry in ancient towns, it is recommended that homestays and cultural industries be integrated and developed. Through the forms of homestay + regional culture, homestay + digitalization, homestay + brand culture, etc., promote the transformation and upgrading of the homestay industry, broaden the homestay industry chain, and promote the integration of tourism and regional economy in the ancient town.
\end{abstract}

Keywords: Integration of Culture and Tourism, Dujiangyan, Homestay Industry

\section{Introduction}

\subsection{The Development of Ancient Town Homestay Ushered in New Opportunities}

In recent years, Sichuan has accelerated the construction of a strong cultural province. In 2019, the "Medium and Long-term Planning Outline for Building a Cultural Province (2019-2025)" [1] "Opinions on Vigorously Developing the Cultural Tourism Economy and Accelerating the Construction of a Cultural Province and Tourism Province" [2] "Sichuan Province A Level "Implementation Measures for the Integrated Development of Cultural and Tourism Scenic Spots" [3] and other policies, focused on the development goals and new tasks of cultural tourism, vigorously promoted the high-quality supply of cultural tourism resources and products, promoted the innovation of cultural tourism products, improved the quality of cultural tourism services, and guided local governments to actively transform and develop.

It is proposed in relevant tourism development conferences

Sichuan focuses on building a homestay cluster, promoting the sustainable development of rural tourism and boutique homestays, and helping the high-quality supply of cultural tourism resources products and the innovation of cultural tourism product formats. In August 2020, the Sichuan "Great Irrigation District" Cultural Tourism Development Alliance was established in Dujiangyan City, Chengdu. This measure 
also brings new opportunities for the development of Dujiangyan ancient town homestay industry. The existing ancient towns are mainly divided into three typical development modes: cultural tourism, leisure and vacation, and life experience. Considering the tourism development of Dujiangyan, the tourism of the ancient town should be cultural tourism [4], In addition, young consumers have become the main consumers in the market, and they are pursuing individuality and quality, "culture + tourism + accommodation" has become the choice of more and more tourists and the target of more and more operators, and the size of homestays has gradually increased.

\subsection{The Importance of Homestays in Ancient Town Tourism Is Remarkable}

In recent years, the tourism industry in the ancient town has developed rapidly, and the number of tourists has increased year by year. Many tourists have a greater demand for local characteristic homestays in order to have a more in-depth experience of the ancient town, and homestays around the scenic spots have emerged [5], ancient town and homestay complement each other. On the one hand, the ancient town provides the most suitable background support and fertile ground for the development of the homestay. On the other hand, the homestay provides the most critical format element support for the in-depth experience of the ancient town and the extension of the industrial chain, and it bears the cultural heritage, and also plays a role in promoting the development of tourism economy in ancient towns [6], Homestay industry plays a vital role in ancient town tourism. On the one hand, it bears the role of cultural inheritance, on the other hand, it also plays the role of promoting the development of tourism economy, which can make the commercial economy and cultural inheritance of ancient town integrate and develop more effectively. Ruan Songqing and others put forward that the tourism function of ancient towns is mainly reflected in appreciating the beauty of "ancient charm" of ancient towns; appreciate the beauty of ancient town culture and art, watch the natural beauty of ancient town, and experience ancient farming civilization and leisurely pace of life [7]. Compared with the traditional forms of accommodation, homestay industry has more obvious personalized differences, which can be used as a medium to experience the ancient town culture, so that tourists can feel the local customs and customs closely through the products and services of homestay, feel the beauty of nature and humanity in the ancient town through the experience of "home" culture.

\subsection{The Development of Ancient Town Homestay Faces New Challenges}

Under many favorable conditions to promote the development of tourism economy, the development of tourism homestay industry in Dujiangyan Ancient Town is facing new development opportunities as well as new challenges. First, the number of homestays continues to rise, and the investment in the development of homestays continues to increase. However, some homestays develop blindly, their cultural presentation forms are superficial, and their development models are over-commercialized, hollowed out and homogenized, resulting in short life cycle and lack of core competitiveness, which has been eliminated in the wave of rapid development of homestay industry. Secondly, affected by the COVID-19 epidemic, a large number of homwstays were impacted, and they struggled to survive or even closed down in the predicament, while tourists' requirements and standards for homestays were also raised. If they develop higher quality homestays, increase their anti-risk ability and enhance their industrial competitiveness, these problems can not be ignored.

Based on the research and analysis of the development situation of homestay industry in Dujiangyan ancient town, and the background of the integration of culture and tourism, this study puts forward the path exploration of the integration of homestay industry and cultural tourism industry, hoping to provide reference for the development of local homestay industry.

\section{Definition of the Concept of the Integration of Homestay and Cultural Tourism}

\subsection{Homestay Concept}

Homestay is a new form of tourism accommodation, which is different from ordinary hotels and other accommodation facilities. Some scholars believe that the tourist homestay has very distinct local characteristics, is an upgraded version of the agritainment [8], and a place that combines the local natural landscape, cultural environment, ecological resources and production and lifestyle to provide local accommodation experience services for tourists [9]. In 2019, "Basic Requirements and Evaluation of Tourism homestay" newly issued by National Tourism Administration defined that tourism homestay is a small accommodation facility for tourists to experience the local nature, culture and production lifestyle, with no more than 4 floors of business rooms and no more than 800 square meters of building area. It can be seen that homestay should be a form of accommodation integrating natural environment, customs, historical background and cultural connotation, and also an extension product of "home culture".

\subsection{Concept of Integration of Culture and Tourism}

Under the background of the new era, the integration of culture and tourism is the new goal and mission of practicing socialism with Chinese characteristics in China. Its purpose is to promote the transformation and upgrading of culture and tourism and meet the needs of the people for a better life. The integration of culture and tourism is driven by many factors, such as product innovation, technological progress and expanding market demand. By excavating cultural value and 
integrating it with tourism elements from the inside out, culture and tourism can penetrate each other and further develop, and finally realize the transformation and upgrading of new formats, new functions and new products [10]. "Culture is the soul of tourism, and tourism is an important carrier of culture." The deep integration of culture and tourism is an effective means to promote the rapid development of cultural and creative industries, enhance the soft power of national culture and accelerate industrial upgrading.

\section{Research on the Integration of Culture and Tourism}

At present, the research on cultural and tourism integration involves various types of tourism industries. Due to the differences of each industry in its own characteristics, development speed and technology, the development paths of cultural and tourism integration proposed by scholars from the theoretical or practical level also have their own advantages and disadvantages. In order to better promote the development of cultural and tourism integration in ethnic areas, Kong Kai and others put forward a multi-integrated cultural and tourism integration model and a guarantee path for cultural and tourism integration [11]; Feng Jiqiang and others put forward the form of $5 \mathrm{G}+$ intelligent cultural tourism based on the background of cultural tourism integration to promote the development of cultural tourism integration in libraries [12]; Wang Jianqin and Li Gang proposed that there are three strategic modes of cultural tourism integration: culture + tourism, tourism + culture, and cultural tourism + other. It is necessary to solve the obstacles to the development of cultural tourism integration through conceptual adjustment and institutional guarantee [13]; Zhou Lingling put forward the comprehensive layout of Chengdu rural revitalization path from the perspective of cultural tourism integration, differentiated customization, shaping cultural tourism brands, driving the sales of cultural tourism products, designing tourism activities related to cultural experience, and cultivating the professionalism of employees [14]; Ren Zhiyan, etc., based on the background of cultural tourism integration and the development condition of Shaanxi History Museum, put forward two paths: cultural resources activation and tourism environment activation [15]; according to the actual situation, Hu Haisheng and others put forward that the development path of cultural and tourism integration in Jiangxi Province includes establishing the integration concept, innovating the integration format, optimizing the integration layout, cultivating the integration subject, and consolidating the integration foundation. In the aspect of the integration and development of cultural tourism and homestay industry, it is mostly based on the practical basis to explore the path of industrial integration and development. For example, Zhang Jie and He Dandan took Changshun County as an example, and proposed the integration and development of agricultural products and homestays, and actively built the brand of agricultural products and homestays [16]; from the perspective of the integration of culture, tourism and agriculture, Zhang Cuili and Liu Yuefang took Wuyi District of Jiangmen as an example, some suggestions are put forward, such as building the brand of homestay, optimizing the product structure of homestay+ and rural regional cultural connotation, strengthening the interaction between hosts and guests, strengthening the online marketing of mobile terminal and standardizing the industry standards [17].

\section{Development Condition and Main Problems of Tourist Homestay Industry in Dujiangyan Ancient Town}

\subsection{Development Condition of Homestay Industry in Dujiangyan Ancient town}

In recent years, Dujiangyan has vigorously promoted the development of homestay industry, taking it as an important work to upgrade tourism work and an important way to enrich people and increase income. With the hot development of the homestay market, individual homestays developed by relying on scenic spots are constantly emerging, forming a homestay cluster with Dujiangyan scenic spot as its core. By visiting the homestay in Dujiangyan ancient city and according to the data of Tujia, Ctrip, Airbnb and other platforms, the existing homestays are mainly divided into apartments, ordinary houses, small villas and other types, which are mainly distributed in West Street, Baoping Lane, Xingfu Road and other places near Dujiangyan scenic spot. The surrounding traffic is accessible, the natural environment is beautiful, the history and culture are profound, tourists are the main customer groups, and the business is greatly affected by the low and peak tourist seasons.

\subsection{The main Problem}

\subsubsection{Individual Homestays are in Their Own Ranks, with Weak Brand Awareness}

Our country's homestay industry has entered a bottleneck period after experiencing a skyrocketing development. At this stage, the process of building a homestay brand is facing challenges such as weak brand awareness, inaccurate market positioning and insufficient professional talents. Combined with the current situation of the Dujiangyan homestay industry, the above problems also exist. Under the promotion of the local government and the media, some high-end boutique homestays have formed their own brands, but most of the smaller homestays have slow development and weak brand awareness, making it difficult to form their own brands. Homestays are in separate formations, most of which are self-employed and are in a competitive state. Compared with chain.

\subsubsection{Low Market Entry Barriers and Lack of Professional Talents}

The current national standards for the homestay industry 
and various local standards stipulate the facility configuration and service standards of homestays, but the entry thresholds for the homestay industry are relatively low. More people appreciate the high profit value of homestays, but under a lack of preliminary investigations and preparation entering this industry, the quality of the landlord is uneven, the management and service personnel involved in the cultural level are different, and the operation and management experience is insufficient, which indirectly lead to the difference in the quality, it also indirectly leads to the unevenness of the quality, hardware, and service levels of homestays are uneven, which make it difficult to meet the current market situation of pursuing high-quality services. Therefore homestay industry loses some repeat customers.

\subsubsection{The Characteristics of Regional Culture Are Not Obvious, and the Convergence of Products and Services Is Gradually Revealed}

At present, the post- $90 \mathrm{~s}$ and post- $00 \mathrm{~s}$ are gradually becoming the main force in the tourism consumption market. Consumers are highly educated, prefer personalized consumption, and pay more attention to the quality and connotation of products [18], which shows that the high-end and personalized tourism market has considerable economic benefits. Judging from the existing local homestays, the decoration styles generally pursue Japanese style, European simplicity style, new Chinese style, etc., ignoring local cultural characteristics, or forcibly adding local cultural elements for "mix and match", and few homestays can highlight local customs and regional cultural characteristics. Some homestays gradually move away from the essential meaning of homestays, only providing accommodation services for tourists, and gradually converging to hotels and hotels in terms of decoration, configuration and service, ignoring folk culture and humanistic care. At present, some homestays begin to develop profit models such as $\mathrm{B} \& \mathrm{~B}+$ Wenchuang and $\mathrm{B} \& \mathrm{~B}+$ Catering, but most of them are still single profit models based on accommodation, and their market competitiveness is weak.

\subsubsection{The Network Operation Level of Shared Homestays Is Uneven}

With the continuous development of Internet technology, various tourism and homestay platforms have sprung up, providing strong support for the sustainable development of the homestay industry. According to China Shared Accommodation Development Report (2019), in 2018, the number of houses on major shared accommodation platforms will be about 3.5 million, an increase of $16.7 \%$ over the previous year, the transaction scale will grow steadily, and the market as a whole will be in a rapid rising stage. Especially under the influence of the epidemic this year, many homestays rely on the network platform to promote and release the pre-sale information of houses during the National Day to alleviate the impact of the epidemic. It can be seen that relying on the network platform to build a shared homestay industry has become a necessary means to promote development. However, through investigation, it is found that the network operation managers of local homestays have different levels, they have one-sided knowledge of platform operation technology, and have weak awareness of platform marketing and sustainable operation.

\section{Suggestions on the Integration and Development of Homestays and Cultural Industry}

\subsection{Homestays + Regional Culture}

As a cultural carrier, B\&B should reflect regional culture, custom inheritance and humanistic feelings. While promoting the development of tourism economy, it should combine modernity with tradition, pay attention to inheriting and protecting local culture, and combine the creation of characteristic homestays with tourism resources to highlight regional cultural value, enhance tourists' sense of regional belonging and cultural identity, and promote the sustainable development of homestays. First of all, the tourism resources in Dujiangyan ancient town are rich and varied, with profound historical and cultural background. The resources such as Dujiangyan scenic spot, tea-horse culture, Ming city wall, south bridge, water culture, farming culture and folk festivals are dazzling and have great functional value. Besides, the spiritual and cultural values contained in them are more meaningful in contemporary times. Secondly, there are Tibetan, Qiang, Hui, Yi and other ethnic minorities living in Dujiangyan ancient town. All ethnic groups have unique customs, culture and art. In the process of building and designing the homestay, the unique ethnic colors, symbols, history and culture are integrated into it, so that the ethnic culture can penetrate into the design, products and services of the homestay, which is conducive to upgrading and building the homestay and providing a stable carrier and publicity channel for the development of cultural industries with ethnic characteristics. In addition, Dujiangyan has many intangible cultural heritages such as folk literature, folk music, traditional handicrafts, festival folk customs, food and so on. Injecting intangible cultural heritage into the homestay industry is an effective means to promote the integration, unification and mutual promotion of the protection and inheritance of cultural tourism industry and intangible cultural heritage. It can be seen that taking the characteristic culture of homestays as the soul and Dujiangyan natural and cultural resources as the foundation, we can develop homestay tea horse culture, homestay + ancient architecture culture, homestay + water culture, homestay + national culture, homestay + intangible cultural heritage, homestay+ cultural and creative products and other integration forms, which can make the value of homestay not only reflected in the accommodation function, but also in the decoration design, product creation and service experience of homestay.

\subsection{Homestay + Digitalization}

The Opinions on Further Stimulating the Consumption 
Potential of Culture and Tourism issued by the General Office of the State Council puts forward "promoting the integration of culture, tourism and modern technology". Digitalization has become an important starting point for promoting the integration and development of cultural tourism industry and an important support for high-quality development. Cultural tourism + digitalization has become a new direction for the integration and development of cultural tourism industry [19], and homestay + digitalization will also become an inevitable trend. The integrated development of $\mathrm{B} \& \mathrm{~B}+$ digital cultural tourism industry is conducive to breaking the geographical restrictions, increasing exposure, expanding customer groups and providing intelligent and innovative services for customers. It can be seen from the COVID-19 epidemic that some homestays have reduced the impact of the epidemic through online operation, pre-sale in advance, issuing discount coupons and other online publicity and marketing models, and even promoted the rapid development of shared homestays. The hotel industry has also realized the importance of developing online operation and accelerated the deepening reform of the hotel industry. The integration and development of homestay industry and digitalization requires the joint efforts of people at all stages in the industry: the government can formulate standards and policy support for the development of digital homestay; digital enterprises need to strengthen publicity and training, provide learning and training resources for the host users, and improve the ability and literacy of employees; employees of homestay should improve their awareness of digital development, follow up market changes, continuously learn digital skills, and strengthen their professionalism.

\subsection{Homestay + Brand Culture}

Brand is an intangible asset, representing the cultural core and market competitiveness of homestay, which is conducive to expanding the popularity and reputation of homestayand making homestay stand out in the fierce market competition. To build a brand, homestay needs to find the right market position, tap its own cultural connotation, enhance its core competitiveness, and create unique homestay products in the form of homestay + brand to promote the sustainable development and high-quality construction of homestay. In addition, brand building needs strong brand promotion, which can be carried out through government-led publicity, multi-media and multi-form presentation, cross-border and cross-cultural communication, strengthening the use of digital technology, and flexibly promoting it in various aspects.

\section{Research Conclusion and Prospects}

With the continuous enhancement of the country's soft power and the continuous upgrading of the consumer market, the integration of culture and tourism has become an inevitable trend in the tourism market and a necessary way to promote the transformation and upgrading of the tourism industry in the new era. Under the background of the integration of culture and tourism, promoting the deep integration of characteristic cultural tourism and homestays requires the joint efforts of the government, society and homestays, building homestays according to the ideas of quality, aggregation and art, and taking standardization and personalization as the industry consensus. Based on the integration of culture and tourism, this paper explores the integration path of homestay industry and cultural tourism. By analyzing the development status of homestay industry in Dujiangyan ancient town, it focuses on exploring the integration development path of cultural tourism and ancient town homestay industry, hoping to promote the integration development of homestay industry and cultural tourism, promote the transformation and upgrading of homestay industry, broaden the industrial chain of homestay and promote the regional economic integration of ancient town tourism. This paper only takes the cultural tourism-type ancient town in the main urban area of Dujiangyan City as an example, and in the follow-up research, it will expand the research scope, strengthen the attention to leisure vacation and life experience ancient town tourism around the city, and further explore the existing problems in the development of residential accommodation, so as to broaden the path of the integrated development of residential accommodation and cultural and tourism industry.

\section{References}

[1] Sichuan Provincial people's Government, 2019. Outline of the medium-and long-term Plan for Building a culturally strong Province (2019-2025).

http://sc.gov.cn/10462/10464/10797/2019/5/6/91ec9a5ac16a4 e6c9697d34812b9ee78. Shtml.

[2] Sichuan Provincial people's Government, 2019. Opinions on vigorously developing Culture and Tourism economy and speeding up the Construction of a Province with strong Culture and Tourism

http://sc.gov.cn/10462/10464/10797/2019/4/30/cb0ea36cea04 475ab7ebc3953ebba351.shtml.

[3] Sichuan Provincial Department of Culture and Tourism, 2019. "practical guidelines for the Development of Culture and Tourism in Sichuan Province Grade A Scenic spots" http://wlt.sc.gov.cn/scwlt/gs gg/2019/12/30/1a9d47d5e80a42bfb5fd111ed 38f28fc.shtml.

[4] Chen, Z., 2019. Thoughts on the development of rural tourism in the ancient town of Wangcheng District. Shanxi Architecture 45 (20), 33-34.

[5] Tang, S., W., Zang, L., G., 2018. A study on the development of residential accommodation in ancient towns in underdeveloped areas-- A case study of Huangyao Ancient Town in Hezhou. Business economy (8), 60-62.

[6] Wang, X., Wang, G., Q., Li, Y., 2020. The predicament of the development of ancient towns and residential accommodation and the direction of the new stage. China Travel News (003).

[7] Ruan, S., Q., Wang, J., Luo, Y., Y., 2009. The development status and suggestions of tourism resources in ancient towns of Sichuan. resource development and market 25 (10), 957-960. 
[8] Zhu, Y., H., 2018. Opportunities and challenges of rural tourism $\mathrm{B} \& \mathrm{~B}$ industry under the background of sharing economy. Agricultural Economy (07), 113-115.

[9] Wei, Y. N., 2020. Study on the sustainable development path of Beijing rural housing industry under the background of rural revitalization strategy. Ecological Economy 36 (09), 135-141.

[10] Zhong, H., M., 2020. Theoretical analysis on the integration development of rural tourism industry under the background of integration of culture and tourism. Resource Development and Market 36 (04), 421-426.

[11] Kong, K., Yang, G., H., 2020. Ethnic minority areas rural path brigade fusion research [J/OL]. Social scientists 9, 72-77 [2020-12-02].

http://kns.cnki.net/kcms/detail/45.1008.C.20201127.1513.024. html.

[12] Feng, J., Q., Xu, Y., M., 2020. 5G+ Intelligent Cultural Tourism: A New model of integrated development of library cultural Tourism. Books and Intelligence 04, 79-83.

[13] Wang, J., Q., Li, G., 2020. Fusion of literature and travel: logic, mode, path. Sichuan Opera 10, 182-184.

[14] Zhou, L., L., 2020. Research on the path of rural revitalization in chengdu from the perspective of cultural and tourism integration. Journal of jiamusi vocational college 36 (01), 273-274.

[15] Ren, Z., Y., Zhang, L., Q., 2020. Chen, W., Q., Chen, N., N., 2020. Research on the tourism activation path of cultural resources in Shanxi History Museum under the background of cultural and tourism Integration. Journal of xi'an university of arts and sciences (social sciences edition) 23 (02), 95-100.

[16] Zhang, j., He, D., D., 2019. Research on the development of agricultural products and homestay under the integration of "tourism+ agriculture" industry -- A case study of changshun county. Contemporary Economics (08), 116-118.

[17] Zhang, C., L., Liu, Y., F., 2020. A Study on the Development Strategy of Rural Home Stay Accommodation from the Perspective of Cultural tourism and Agriculture Integration -A Case study of Wuyi Area in Jiangmen. Journal of Sichuan Tourism University 2020 (06), 37-40.

[18] Qi, Z., 2020. Analysis on sustainable Development Strategy of Rural B\&B Tourism under the Construction of Beautiful Countryside. Agricultural Economics (08), 64-65.

[19] Xia, J., C., He, S., J., Xu, J., H., 2020. Digitization: a new direction for the integrated development of cultural tourism industry. Heilongjiang Social Science (02), 51-55+159. 